\title{
Effective Motorcycle Lane Configuration Thailand: A Case Study of Southern Thailand
}

\author{
Sulkiflee Mama ${ }^{\mathrm{a}, *}$ and Pichai Taneerananon ${ }^{\mathrm{b}}$ \\ Centre for Road Safety Research, Department of Civil Engineering, Prince of Songkla University, Hat Yai, \\ Songkhla 90112, Thailand \\ E-mail: akeeyotha@yahoo.com (Corresponding author), bbreathislife@yahoo.com
}

\begin{abstract}
Motorcycle lane has proved to be an effective engineering measure in reducing motorcycle crashes and fatalities. Its effectiveness stems from the fact that it helps mitigate the hazards of riding a motorcycle in a traffic stream, which have become a serious cause of death and injury in many countries. This research seeks to develop standardized configurations and widths for motorcycle lanes in Thailand. The optimum format for such a lane may be determined from the simulation of data relating to road accidents, traffic volumes and vehicle speeds. In practice, a range of initial lane widths were inputted into a traffic simulator program - in this case, the VISSIM 5.4 - whose output was analyzed to yield the relationship between MC volume, lane width and level of service (LOS). A pilot test was then performed on a stretch of actual road which had been installed with an MC lane of varying widths. Changes in vehicle speed were observed and employed to determine the relationship between lane width and the actual reduction in vehicle speed and the theoretical reduction in road accidents. Findings of the study point to an efficient lane width in the range of 2.0 to $3.0 \mathrm{~m}$ - for the shared lane configuration. For any width outside the said range, the benefit of the MC Lane would be eroded either by the intrusion of larger vehicles, or by the constraining effect of too narrow a lane. The authors also recommends the preferred width for an Exclusive MC Lane which may range from 3.0 to $4.0 \mathrm{~m}$. The lane width of $3.0 \mathrm{~m}$ is found to be the most effective in reducing the speed of all traversing vehicles, even when compared with the $2.5 \mathrm{~m}$ or $3.5 \mathrm{~m}$ widths. With the $3.0 \mathrm{~m}$ option, the resulting reduction in speed can be as high as $17 \%$; and reduction of accidents, up to $25 \%$. In view of the aforementioned, the authors recommend configuring for the Shared Motorcycle Lane of $3.0 \mathrm{~m}$ with 2 sublanes of $1.5 \mathrm{~m}$ width, and for the Exclusive Motorcycle Lane $3.0-4.0 \mathrm{~m}$ with 2 sublanes of 1.5 to $2.0 \mathrm{~m}$ width.
\end{abstract}

Keywords: Motorcycle lane, lane width, motorcycle speed.

ENGINEERING JOURNAL Volume 20 Issue 3

Received 29 July 2015

Accepted 28 October 2015

Published 19 August 2016

Online at http://www.engj.org/

DOI:10.4186/ej.2016.20.3.113 


\section{Introduction}

Road traffic accidents have become a problem of global proportions. Recent estimates by the World Health Organization put the worldwide road crash fatality rates at 1.24 million deaths per year, about $59 \%$ of which affecting people in the 15-44 age group; while the life of 50 million more is made difficult by serious injuries. The daily global average of number of road fatalities is 3,400. For countries with a low or medium GDP, including Thailand, the percentages of deaths by road crashes are as high as $90 \%$ of the global fatality; while the remaining $10 \%$ shared by the higher-income nations. About $50 \%$ of the global road deaths involved the vulnerable road users including MC riders, pedestrians and cyclists - at $23 \%, 22 \%$ and $5 \%$ respectively [1]. Southeast Asia is noted for its high ranking in road deaths when compared with those occurring in other regions. For Thailand, some $74 \%$ of road deaths involved MC users. Following Thailand are Cambodia, at 63\%; Indonesia, at 61\%; Malaysia, at 58\% and Singapore, at 58\% [2]. A global accident survey covering 193 countries by the Michigan University's Transport Research Institute, featuring a comparison of traffic-induced fatalities against those caused by illnesses, listed the average global crashinduced deaths at 18 per 100,000 people. Topping the list is Namibia with a ratio of 45 deaths per 100,000 population - far above the average. Thailand comes in a close second - at 44 deaths per 100,000; while Maldives has the lowest ratio of 2 per 100,000. The global average for fatalities from road crashes as a percentage of fatalities from other leading causes was found to be $2.1 \%$. Nonetheless, Thailand's ratio is a whopping $5.1 \%$, or more than doubling the global average. Road crash fatalities in Thailand are surpassing deaths caused by other diseases: the road deaths are higher than those caused by heart diseases $(55.8 \%$ higher); or malignant cancer ( $42.1 \%$ higher); or brain hemorrhaging ( $40.6 \%$ higher) [3]. Malaysia has taken the initiatives to implement a range of measures designed to reduce road accidents and protect the MC riders; constructing MC lanes is a key measure. The MC lanes segregate the traffic of large vehicles from the MCs, and at the same time, help to improve the sight distance of the drivers of trucks and cars. The move has helped reduce accidents by $39 \%$, and MC deaths by $83 \%$ [4]. Initiatives of this kind are being actively pursued in Thailand. The Road Safety Master Plan 2009 - 2012 by the Center for Road Safety, Department of Disaster Prevention and Reliefs, has set out strategies and guidelines for installing MC lanes on community roads and on routes where there is a high degree of mixing MCs with other vehicles.

This paper sets out the principles and methodology for developing suitable MC lane configurations. It is the author's hope that the paper will offer some insights for the establishment of MC lanes.

\section{Literature Review}

The authors conducted an exhaustive review of available literature on road safety in Thailand, and motorcycle (MC) speed and a selection of computer programs for local-area traffic simulation. Results of the review are summarized below.

One of the many challenges in Thailand road safety is the low safety records of inter-city travel with its high casualty rate as a consequence of roadside crashes, a study has shown that the situation could be improved by simply following the clear zone guideline more closely [5]. Safety at intersection is also a challenge, as MC riders often disobey traffic signals. The situation is made worst during construction to upgrade an at-grade intersection to grade separated junction, when casualties are increased [6]. On the issue of driving behavior, speed is probably the key challenge and the most-frequently cited factor contributing to motorcycle crashes. It has been found that in a traffic stream, MCs tend to have higher speeds than do cars at the beginning of movement after the green light, but in mid-stream MC speeds fall below those of cars. Along narrow streets MCs would have a higher speed [7]. Using laboratory experiments and roadside observation [8] it was concluded that motorcyclists would typically go for faster speeds than car drivers would; and that younger people generally travel faster than older road users [9]. A study of MC crashes in Europe by MAIDS team [10] found that the difference in the traveling speed of MCs relative to that of the surrounding traffic has a direct bearing on $66 \%$ of the crashes involving MCs. In traffic safety terms, pedestrians, cyclists, and riders of motorized two-wheelers and their passengers are collectively known as "vulnerable road users". According to [1] the proportion of road traffic deaths occurring to vulnerable road users is greater in low-income countries than that in high-income countries. Only 59 countries, covering $39 \%$ of the world's population (or 2.67 billion people), have imposed a measure of urban speed limit, which is typically $50 \mathrm{~km} / \mathrm{hr}$ or less; and local authorities are allowed to further reduce such a limit. The positive effect of speed reduction has been the subject of intensive studies in Europe and the U.S. in recent decades. 
Field evidence from such studies has verified that: a $5 \%$ cut in the mean traffic speed can contribute to a reduction in the number of fatal crashes by as much as $20 \%$ [11]; and a decrease of $1.0 \mathrm{~km} / \mathrm{hr}$ of the same can result in a $3 \%$ decrease in the number of injury crashes (or a decrease of 4 to $5 \%$ for fatal crashes). By contrast, where the mean speed is raised by a mere $1.0 \mathrm{~km} / \mathrm{hr}$, the corresponding increases in injury crashes and fatal crashes are $3 \%$ and $>4 \%$ respectively [12].

For Thailand, the idea of MC lane has been around for decades, although rigorous application of this road feature has yet to take hold. On 29 July 2000, the Thai Cabinet approved pilot tests for four MC lane configurations: 1) a one-way lane on the shoulder of the Chiang Mai-Mae Rim Highway, having a $2.0 \mathrm{~m}$ width and being marked out with a white $0.1 \mathrm{~m}$ edge line; 2) a lane between a car lane and the road shoulder - two instances of this were set up in Phuket and Lampang provinces; 3) a semi-exclusive MC lane in Tak province where it is positioned on a strip along the left of the road shoulder, and marked out with intermittent barriers; and 4) an exclusive MC Lane, the trial for which has not yet been attempted. Despite the insufficient local data on this road feature, the Office of Transport and Traffic Policy and Planning (OTP) has recommended guidelines for setting up MC lanes of varying capacities: For a lane with daily traffic up to 3,000 mc, the guidelines recommend a $2.0 \mathrm{~m}$ lane for a one-way MC stream, to be positioned on a $3.0 \mathrm{~m}$ wide road shoulder; for a daily traffic of $12,000 \mathrm{mc}$, the lane is to be exclusive for a one-way traverse and separated from other traffic lanes by green strips. OTP also suggests the construction of low clearance underpasses at intervals of $3-5 \mathrm{~km}$ for right turns [13]. By contrast, Malaysia sets their MC lane width from $2.5-3.5 \mathrm{~m}$, flanked by a road shoulder of $1-2 \mathrm{~m}$ wide, and good for MC speeds up to 70 $\mathrm{km} / \mathrm{hr}$. According to the study by Radin et.al [14] on the relationship between MC flow rate, density, level of service and lane width, it was found that for an $\mathrm{MC}$ lane of $2.5-3.5 \mathrm{~m}$ width at level of service $\mathrm{E}$, the lane is able to take up 5,300-7,750 mc/hr/ln [15]. In Taiwan, where Intelligent Transportation System has been in use for some years, exclusive $\mathrm{MC}$ lanes are provided together with a setback storage space for left turning motorcyclists at a signalized intersection who are required to do a two-stage turn for safety reason. For an average traffic density of 2,000 CPU or more, Taiwanese traffic code suggests the setting up of exclusive MC lanes as follows: 1) for 1000 cars and 3300 Mcs, the configuration suggested is one car lane of width $3.5 \mathrm{~m}$ and one MC lane of $2.0 \mathrm{~m} \mathrm{2}$ ) for 1800 cars and $660 \mathrm{Mcs}$, two car lanes should be put up and the MC rides non-exclusively on the kerbside strip; and 3) for 200 cars and 6000 Mcs, it is one car lane of width $3.5 \mathrm{~m}$ and two exclusive MC lanes [16]. The above examples attest to the fact that standards governing MC riding and MC lanes differ from one country to the next. Nevertheless, some overseas practices can be emulated for the condition in Thailand; for example the state of Queensland's speed limit for lane filtering MCs which is set at $30 \mathrm{~km} / \mathrm{hr}$ [17]. MC lanes have been adopted in a number of Thai provincial cities including Phuket, Samut Prakan, Nakhon Pathom, Tak and Lampang. Design of these facilities has been "incomplete" due to its lack of exclusivity; for example, at an intersection or U-turn opening, the MC making a turn has to share lane with the car traffic. Only a small number of the urban roads have been designed with a MC lane, but it is often used as a car-parking lane. Notwithstanding such shortcomings, the MC lane still holds potential for further development, ideally as an integral part of road infrastructure to enable a better level of the safety for riders, a goal worth every dollar of investment. [18].

For this study, a number of local-area traffic modeling applications were assessed for their suitability, such as VISSIM, NETSIM, PARAMICS, AIMSUN, and CORSIM. Out of these, the VISSIM program was selected due to its ability to simulate the MC rider's behavior and MC traffic manipulation in much the same way as those for other types of road vehicles. With VISSIM, it is possible to specify the lateral clearance between two vehicles; or the position of a vehicle on a lane, i.e. left, right or middle. A vehicle can be made to overtake a slower machine in front and on the same lane. And while vehicles are waiting at a signalized intersection, the MCs may be simulated to weave in-between the lines of cars to fill gaps at the front of the traffic stream, thereby shortening the waiting lines [19]

The modeling program VISSIM 5.4 was chosen for this study primarily for its ability to simulate MC traffic to match our specified MC lane widths and configurations; and for its comprehensive range of other useful functions.

\section{Methodology and Approach}

The purpose of this study is to assess the range of MC lane widths and lane configurations using the approach described below: 


\subsection{Lane Configurations}

Two lane types were investigated, namely the Shared Lane (SL), which allows other types of vehicles to share the MC lane; and Exclusive Lane (EL), which limits the lane use to only MCs. The parameters for model input were based on the followings: data compiled from the authors' previous studies of road accidents in Thailand between the years 2012 and 2014 [20]; and volumes of total traffic and volumes of MC traffic; traversing velocities at $85^{\text {th }}$ percentile of MC speeds derived from actual surveys on urban and rural roads in the provinces of Songkhla and Narathiwas.

\subsection{Lane Width Determination}

The optimum lane width is determined from traffic simulation using VISSIM 5.4 with lane configuration and width data input, plus analysis of the modeling results in terms of relationships between MC volume, lane width and level of service (LOS). The input parameters for rider behavior were based on the values suggested by the program's user manual and field observations. MC dimensions were chosen at 1.8 to $2.0 \mathrm{~m}$ in length and $0.8 \mathrm{~m}$ in width which are considered appropriate to the traffic features of the test site.

\subsection{Pilot Tests}

Tests were conducted on a stretch of urban road in Narathiwas. MC lanes of varying widths were installed at the test site and the speeds of vehicles traversing the site were measured for each lane width. The relationship between lane width and the resulting traffic speeds was thus obtained. Using the conclusions of the study by Finch DJ, et al [10], a relationship can then be determined that links the drop in vehicle speed with the lane width and the resulting reduction in accidents by vehicle type.

\section{Results and Discussion}

\subsection{Key data and Proposed Criteria for the Motorcycle Lane}

From field data and the outcome of the authors' investigation, the key data and criteria for establishing the MC lane are described below:

Number of fatal and serious injuries - all vebicle types: According to the accident statistics compiled by the authors, the rate of fatalities and serious injuries (or death-injury rate) involving all vehicle types on national highways during 2012-2014 was 24 cases per $100 \mathrm{~km}$ per year. Based on the cited figures, suitable parameters for death-injury rates may be derived for determining the optimum MC lane width. These are: 3 cases $/ 10 \mathrm{~km} /$ year, for rural roads; and 6 cases $/ 10 \mathrm{~km} /$ year for urban roads.

Volume capacity ratio $(V / C)$ : For the pilot tests, a $\mathrm{V} / \mathrm{C}$ ratio above $0.6(0.61$ to 0.70$)$ was employed. This is equivalent to a B level of service (or LOS-B) which represents a traffic stream of moderate density where motorists experience some loss in vehicle maneuverability. The MC lane was configured as a Shared Lane. For the other configuration, i.e. the Exclusive Lane, a V/C ratio over 0.7 , or LOS-C was used. At this level of service, motorists experience some tension in vehicular control as well as less opportunities for lane changing in mid-stream.

Number of MC accidents: Data from the authors' study of MC accidents between the years 2012 and 2014 indicated an MC accident rate of $6 \mathrm{MC} / 100 \mathrm{~km} /$ year. For the purpose of the pilot tests, an $\mathrm{MC}$ accident rate of $1 \mathrm{MC} / 10 \mathrm{~km} /$ year was adopted for tests on rural roads; and $4 \mathrm{MC} / 10 \mathrm{~km} /$ year, for tests on urban roads.

Motorycle Volumes: Analysis of the simulation results from VISSIM 5.4 indicated that on urban roads where the MC density is less than $600 / \mathrm{hr} /$ lane, it is feasible to install an MC shared lane having a LOS grading D. For MC densities higher than 600/hr/lane, an Exclusive Lane is preferable. A parallel situation is applicable to rural roads: Shared Lane for an MC density of less than 500/hr/lane; and Exclusive Lane for any density higher than that. An LOS grading of B with a minimum lane width of $2.0 \mathrm{~m}$ should be used on rural roads.

Motorcycle Speed at $85^{\text {th }}$ percentile: Speed surveys conducted on the MC population on urban roads in Songkhla and Narathiwas provinces indicated an average MC speed of 32 to $35 \mathrm{~km} / \mathrm{hr}$, and the corresponding $85^{\text {th }}$ percentile speed of $40-50 \mathrm{~km} / \mathrm{hr}$. And on rural roads in Songkhla the $85^{\text {th }}$ 
percentile MC speed was found to range from 40 to $80 \mathrm{~km} / \mathrm{hr}$. From the surveyed figures, the suitable $85^{\text {th }}$ percentile values were derived thus: for urban roads, $45 \mathrm{~km} / \mathrm{hr}$ and for rural roads, 60 $\mathrm{km} / \mathrm{hr}$.

Findings of the study are prescribed as the key data and criteria for establishing a motorcycle lane, as shown in Table 1. At any rate, the case for an MC lane needs not be fully covered by all of the criteria therein; an appraiser needs only to consider some of the relevant parameters that match the physical requirement of a location, or known characteristics that comply with the stated criteria.

Table 1. Key data and proposed criteria for establishing the motorcycle lane.

\begin{tabular}{|c|c|c|c|c|}
\hline \multirow[t]{2}{*}{ Description } & \multicolumn{2}{|c|}{ Shared Lane } & \multicolumn{2}{|c|}{ Exclusive Lane } \\
\hline & Built up area & Non-built up area & Built up area & Non-built up area \\
\hline $\begin{array}{l}\text { Number of fatalities } \\
\text { and serious injuries }\end{array}$ & $\begin{array}{l}\text { Less than } 6 \\
\text { cases } / 10 \mathrm{~km} / \mathrm{yr}\end{array}$ & $\begin{array}{l}\text { Less than } 3 \\
\text { cases } / 10 \mathrm{~km} / \mathrm{yr}\end{array}$ & $\begin{array}{l}\text { More than } 6 \\
\text { cases } / 10 \mathrm{~km} / \mathrm{yr}\end{array}$ & $\begin{array}{l}\text { More than } 3 \\
\text { cases } / 10 \mathrm{~km} / \mathrm{yr}\end{array}$ \\
\hline $\mathrm{V} / \mathrm{C}$ ratio & $\begin{array}{l}\text { More than } 0.6 \text {, or } \\
\text { LOS B }\end{array}$ & $\begin{array}{l}\text { More than } 0.6 \text {, or } \\
\text { LOS B }\end{array}$ & $\begin{array}{l}\text { More than } 0.7 \text {, or } \\
\text { LOS C }\end{array}$ & $\begin{array}{l}\text { More than } 0.7 \text {, or } \\
\text { LOS C }\end{array}$ \\
\hline $\begin{array}{l}\text { Number of MC } \\
\text { accidents }\end{array}$ & $\begin{array}{l}\text { Less than } \\
\text { 4Crashes } / 10 \mathrm{~km} / \mathrm{yr}\end{array}$ & $\begin{array}{l}\text { Less than } \\
1 \text { Crash } / 10 \mathrm{~km} / \mathrm{yr}\end{array}$ & $\begin{array}{l}\text { More than } \\
\text { 4Crashes } / 10 \mathrm{~km} / \mathrm{yr}\end{array}$ & $\begin{array}{l}\text { More than } \\
1 \text { Crashes } / 10 \mathrm{~km} / \mathrm{yr}\end{array}$ \\
\hline MC volume & $\begin{array}{l}\text { Less than } 600 \\
\mathrm{MC} / \mathrm{hr}\end{array}$ & $\begin{array}{l}\text { Less than } 500 \\
\mathrm{MC} / \mathrm{hr}\end{array}$ & $\begin{array}{l}\text { More than } 600 \\
\mathrm{MC} / \mathrm{hr}\end{array}$ & $\begin{array}{l}\text { More than } 500 \\
\mathrm{MC} / \mathrm{hr}\end{array}$ \\
\hline $\begin{array}{l}\text { MC } 85^{\text {th }} \text { percentile } \\
\text { speed }\end{array}$ & Less than $45 \mathrm{~km} / \mathrm{hr}$ & Less than $60 \mathrm{~km} / \mathrm{hr}$ & $\begin{array}{l}\text { More than } 45 \\
\mathrm{~km} / \mathrm{hr}\end{array}$ & $\begin{array}{l}\text { More than } 60 \\
\mathrm{~km} / \mathrm{hr}\end{array}$ \\
\hline
\end{tabular}

\subsection{Level of Service for Shared Lane}

For the situation of a Shared Lane, a range of lane widths was inputted for simulation by VISSIM 5.4. Starting from $1.0 \mathrm{~m}$, the width was widened in step increments of $0.25 \mathrm{~m}$ up to the width of $3.5 \mathrm{~m}$. as shown in the graph below. The outcome of the simulation enabled the analysis of the relationship between Lane Width, MC volume and LOS as shown in Fig. 1 below. The graph in Fig. 1 shows that lane widths ranging from $2.0 \mathrm{~m}$ to $3.0 \mathrm{~m}$ were able to accommodate $\mathrm{MC}$ volumes up to a maximum of $600 \mathrm{MC} / \mathrm{hr}$ at the maximum LOS at D level (LOS-D). And at LOS-D, the width of $2.0 \mathrm{~m}$ was able to carry an MC volume of $180 \mathrm{MC} / \mathrm{hr}$. Similarly, the $2.5 \mathrm{~m}$ width could take up $320 \mathrm{MC} / \mathrm{hr}$. (See graph below).

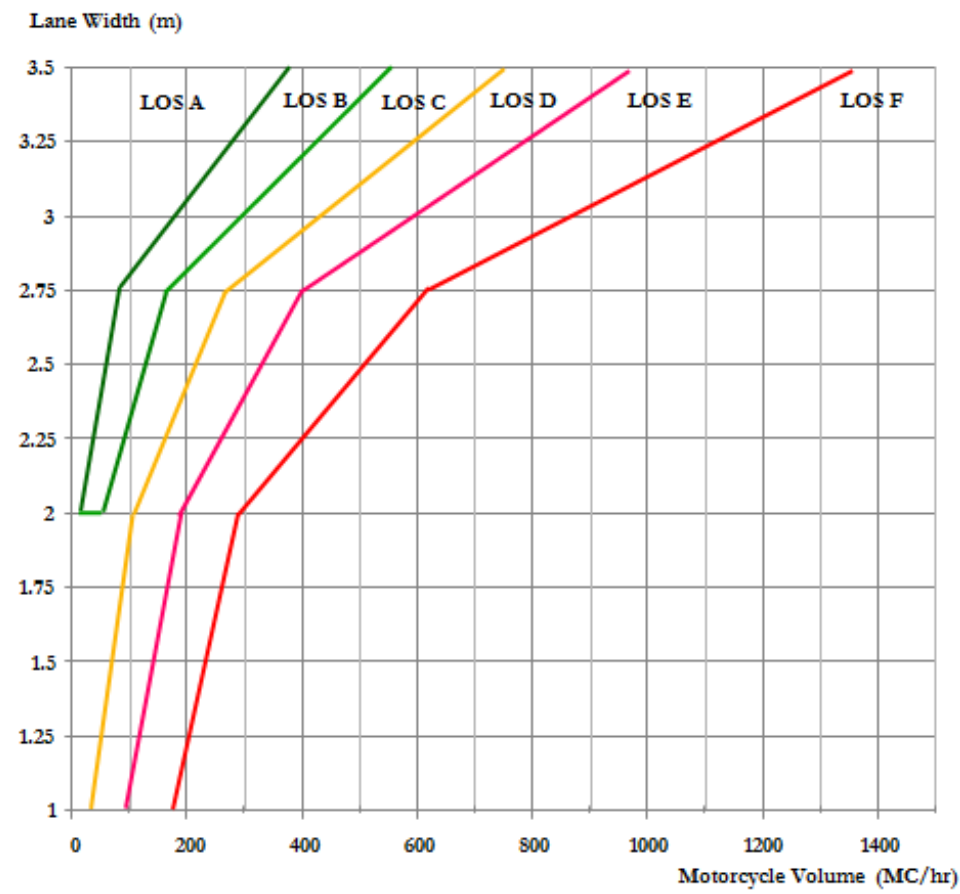

Fig. 1. Relationship between MC volumes, lane width and LOS, on shared MC lane. 


\subsection{Level of Service for Exclusive Lane}

For an Exclusive Lane, the lane width parameters employed for simulation by VISSIM 5.4 was widened in step increments of $0.25 \mathrm{~m}$, starting from $2.0 \mathrm{~m}$ up to $4.0 \mathrm{~m}$ as shown in Fig. 2 below. The outcome of the simulation enabled the analysis of the relationship between Lane Width, MC volume and LOS as shown in Fig. 2. The graph in Fig. 2 shows that, at LOS-D, a 2.0m lane width was able to accommodate 1,000 MC/hr; a $2.5 \mathrm{~m}$ width, $1,060 \mathrm{MC} / \mathrm{hr}$; a $3.0 \mathrm{~m}$ width, $1,120 \mathrm{MC} / \mathrm{hr}$; a $3.5 \mathrm{~m}$ width, $1,335 \mathrm{MC} / \mathrm{hr}$. And the maximum width of $4.0 \mathrm{~m}$ could take up $1550 \mathrm{MC} / \mathrm{hr}$.

\section{Lane Width (m)}

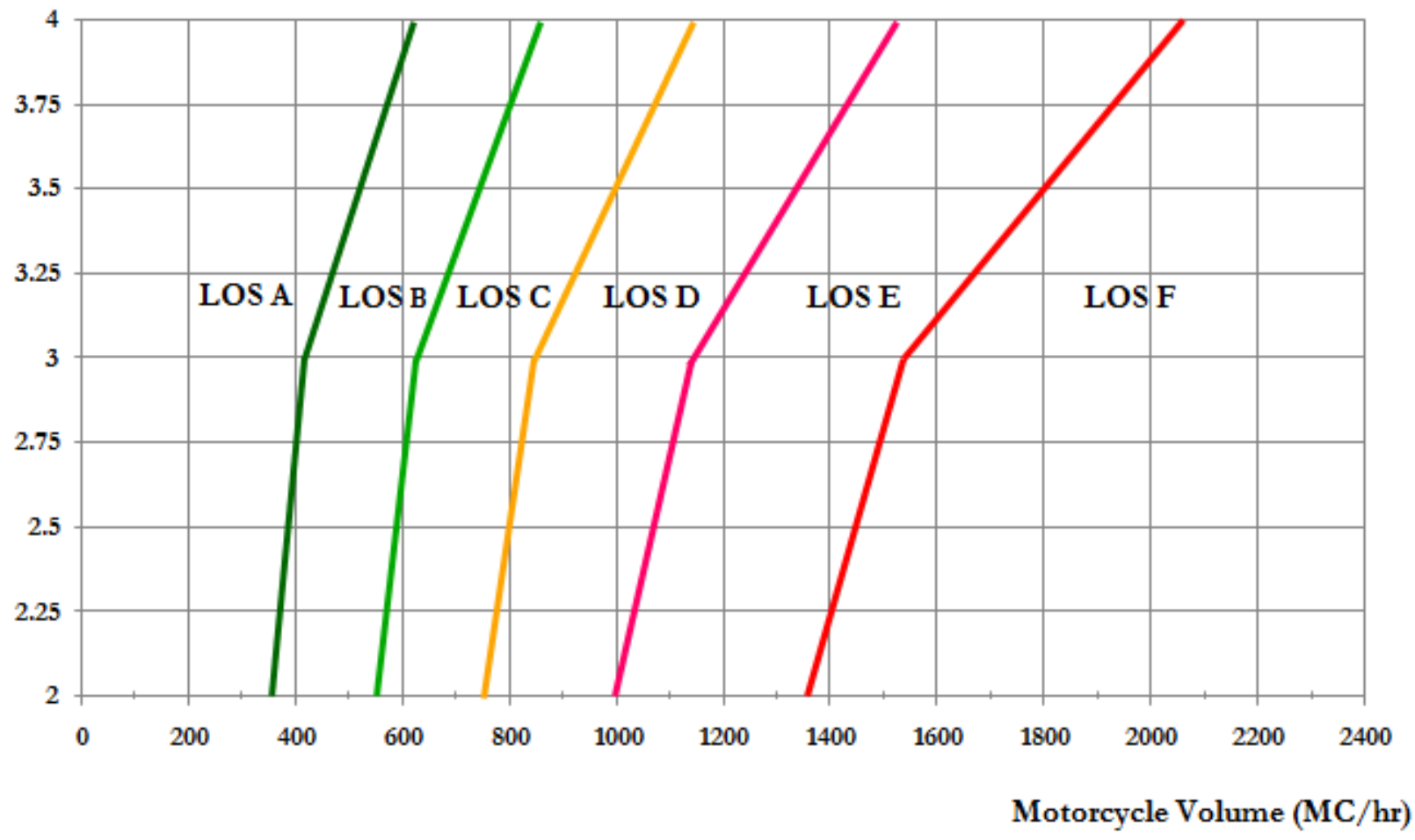

Fig. 2. Relationship between MC volumes, lane width and LOS, on exclusive MC lane.

\subsection{Field Tests of MC Lane Configurations}

Field tests were carried out in Narathiwas province on a 4-lane stretch of an urban road with 2 lanes of traffic per direction. The tests were performed using a range of parameters as follows: $\mathrm{V} / \mathrm{C}$ ratio of $0.6 ; 580$ $\mathrm{MC} / \mathrm{hr}$ density; MC accident rate of 2 Crashes $/ 5 \mathrm{~km} /$ year; and an $85^{\text {th }}$ percentile MC speed of $49 \mathrm{~km} / \mathrm{hr}$. On comparing the cited parameters against the key data and criteria, it was found that the V/C ratio, MC volume and MC accident rate match our criteria for the Shared Lane configuration. However, the $85^{\text {th }}$ percentile speed did not match the criteria; and the death-injury figure was not available in this case. Despite the absence of the latter two parameters, the first three were considered sufficient for field testing a Shared Lane configuration. The tests were performed using three lane widths $-2.5 \mathrm{~m}, 3.0 \mathrm{~m}$ and $3.5 \mathrm{~m}-$ as shown in Fig. 3. From the measurements carried out, it was seen that the installation of an MC lane led to a distinct reduction in the speeds of vehicles traversing the test site, as shown in Figs. 4 and 5. An exception should be noted in the case of MC speeds which showed increases in line with the widening of the MC lane. 


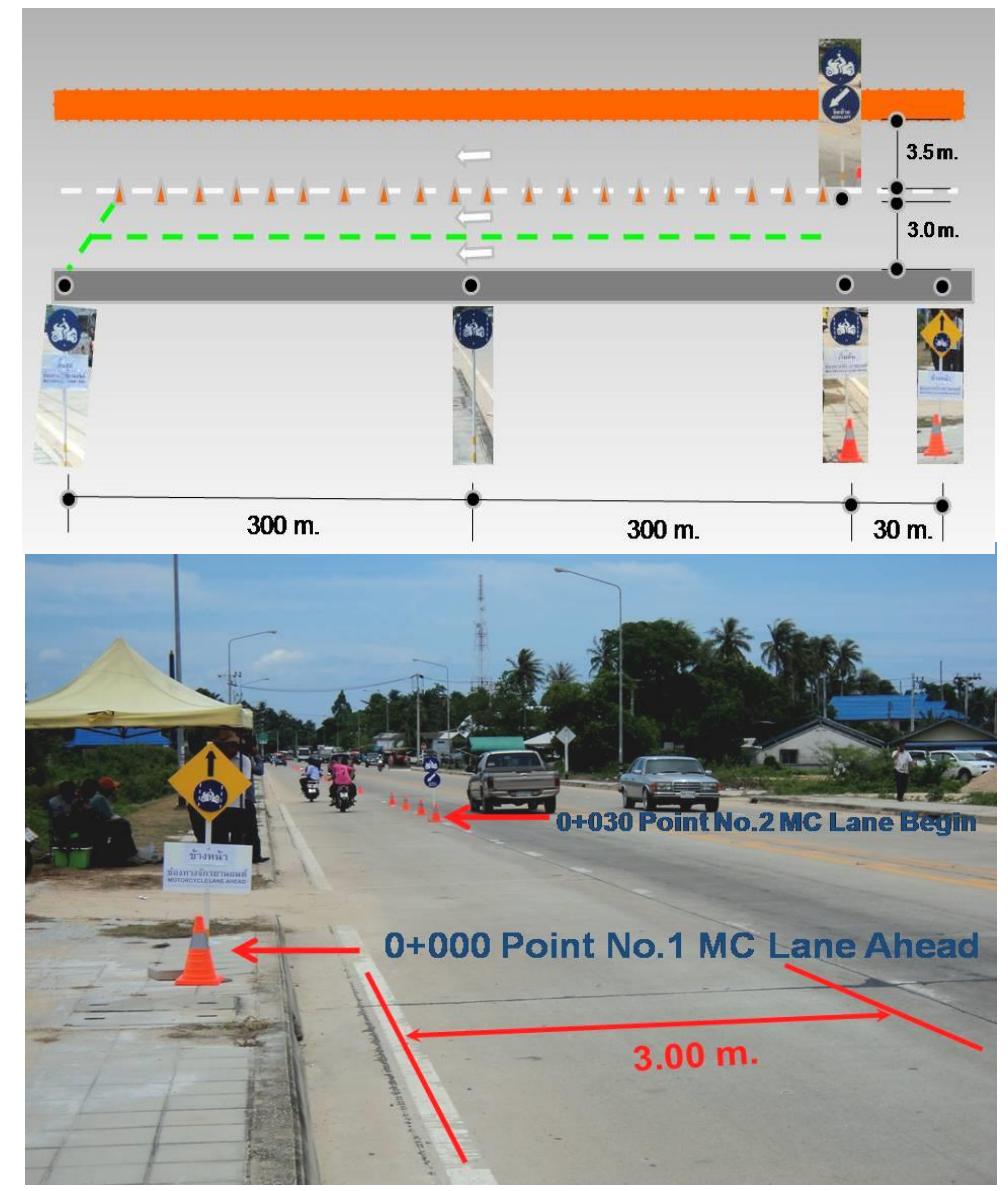

Fig. 3. Field test of MC lane configurations on an urban road in Narathiwas.

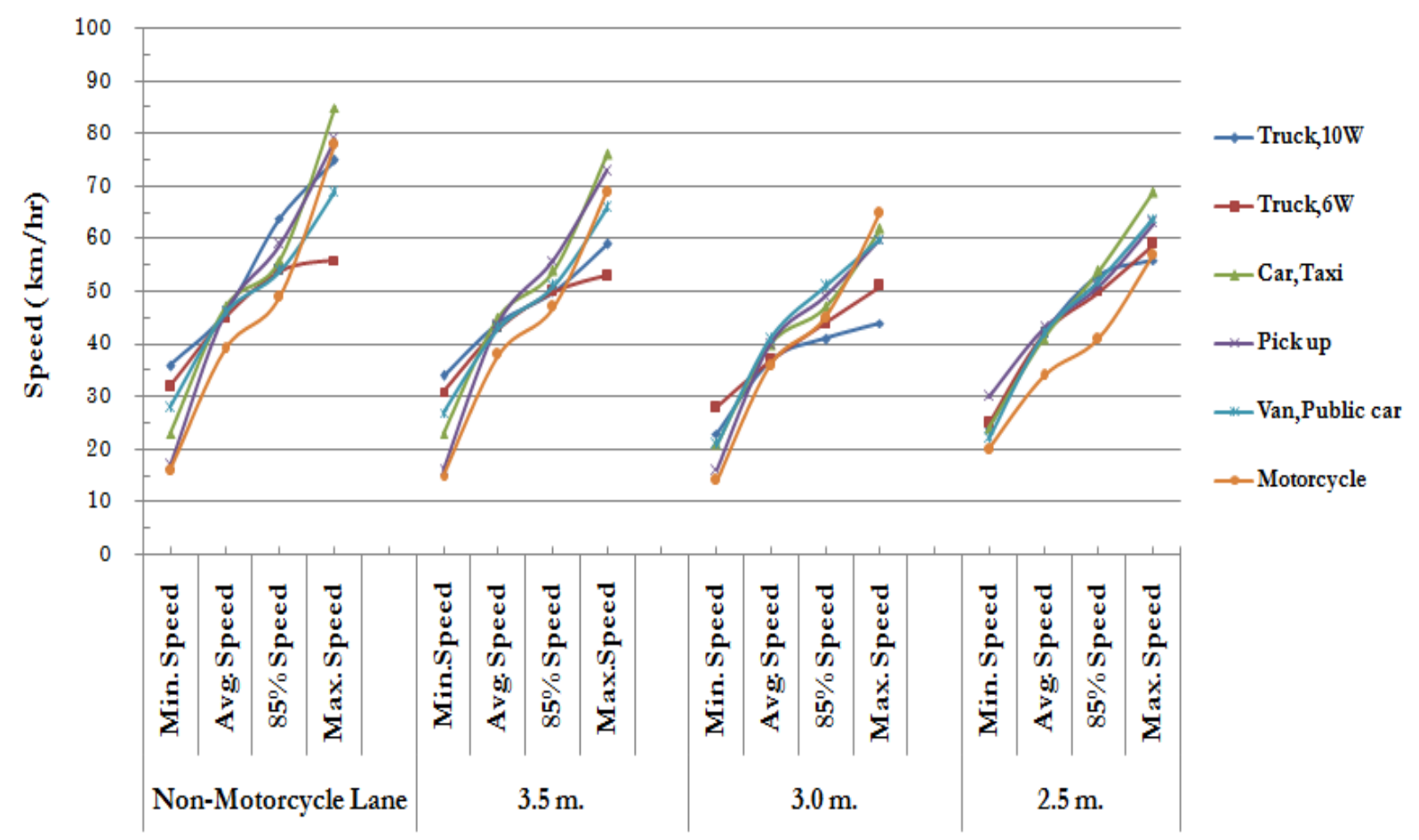

Fig. 4. Speeds of vehicle types in relation to varying MC lane widths. 
From Figs. 4 and 5, it can be seen that the greatest reduction in vehicle speed occurs at the lane width of $3.0 \mathrm{~m}$. At this width, the speed of the 10 -wheel trucks showed a maximum reduction of $36 \%$, which corresponds to an accident reduction of 58.6\%. This is trailed by the speed reductions of the 6 -wheel trucks, the pick-ups, private cars, motorcycles, and vans and public cars. The reductions in speed as well as the corresponding drops in accidents are shown in Fig. 5, along with the average reduction in speed of $17 \%$ and its corresponding $25 \%$ drop in accident rate.

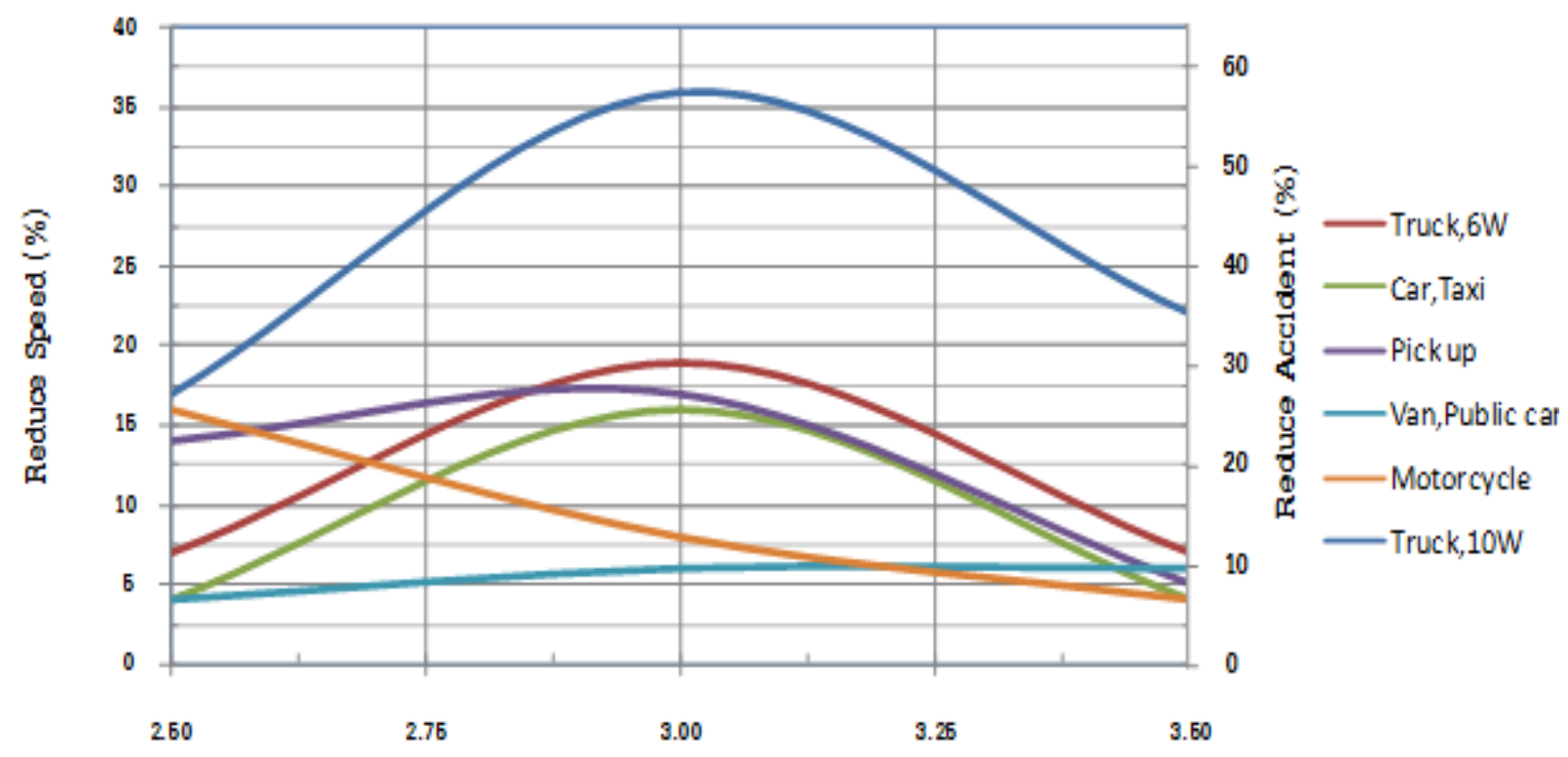

Lane Width $(\mathrm{m})$

Fig. 5. Reductions in vehicle speed and accidents in relation to varying MC lane widths.

\section{Conclusions}

The Shared Lane and Exclusive Lane are the two configurations of MC lanes analysed in the study. The input parameters for simulation are as follows:

\begin{tabular}{|l|l|l|}
\hline \multicolumn{1}{|c|}{ Parameter } & \multicolumn{1}{|c|}{ MC Lane on a Rural Road } & \multicolumn{1}{c|}{ MC Lane on an Urban Road } \\
\hline Fatal/serious injuries & 3 cases $/ 10 \mathrm{~km} /$ year & 6 cases $/ 10 \mathrm{~km} /$ year \\
\hline Number of MC accidents & $1 \mathrm{Crash} / 10 \mathrm{~km} /$ year & 4 Crashes $/ 10 \mathrm{~km} /$ year \\
\hline MC volume & $500 \mathrm{MC} / \mathrm{hr} / \mathrm{lane}$ & $600 \mathrm{MC} / \mathrm{hr} / \mathrm{lane}$ \\
\hline MC $85^{\text {th }}$ percentile speed & $60 \mathrm{~km} / \mathrm{hr}$ & $45 \mathrm{~km} / \mathrm{hr}$ \\
\hline & \multicolumn{1}{|c|}{ Shared Lane } & Exclusive lane \\
\hline V/C ratio & $>0.6$ or LOS-B & $>0.7$ or LOS C \\
\hline
\end{tabular}

Findings of the study indicated the optimum width of a Shared Lane lies in the range $2.0 \mathrm{~m}$ to $3.0 \mathrm{~m}$. At these widths, the MC lane should be able to accommodate traffic from 180 to $300 \mathrm{MC} / \mathrm{hr} / \mathrm{lane}$. Widths greater than $3.0 \mathrm{~m}$ will tempt the larger vehicles to stray into the lane, hence eroding its benefit for the MCs. On the other hand, a width less than $2.0 \mathrm{~m}$ will most likely be too restrictive to provide any benefit (the typical body width of a motorcycle being $1.8 \mathrm{~m}$ ). The recommended width of $3.0 \mathrm{~m}$ should provide an optimum benefit even when compared with $2.5 \mathrm{~m}$ and $3.5 \mathrm{~m}$ lanes. It has been tested and found to reduce the speeds of other traversing vehicles by $17 \%$ on average, which translates to an average reduction in accidents of $25 \%$.

In the case of an Exclusive Lane, the recommended width is between $3.0 \mathrm{~m}$ and $4.0 \mathrm{~m}$ per direction depending on the volumes of traversing MCs. The Exclusive Lane may be divided into 2 sublanes, or $1.5 \mathrm{~m}$ to $2.0 \mathrm{~m}$ per sublane. In summary, the authors recommend configuring both the Shared and Exclusive 
Lanes as 2-sublane per travelling direction, or $1.5 \mathrm{~m}$ to $2.0 \mathrm{~m}$ per sublane. Such a configuration should encourage the orderly riding of the MCs, and at the same time, provide ample room for coping with the future growth of the MC volumes.

\section{References}

[1] WHO, "Global status report on road safety 2013," 2013.

[2] WHO, "Global status report on road safety: Time for action 2009," 2009.

[3] M. Sivak and B. Schoettle, "Mortality from road crashes in 193 countries: A comparison with other leading causes of death," The University of Michigan Transportation Research Institute, Rep. UMTRI-2014-6, 2014.

[4] R.S. Radin Umar, M. Mackay, and B. Hills, "Multivariate analysis of motorcycle accidents and the effects of exlcusive motorcycle lanes in Malaysia," Journal of Crash Prevention and Injury Control, vol. 2, no. 1, pp. 11-17, 2000.

[5] O. Somchainuck, P. Taneerananon, and S. Jaritngam, "An in-depth investigation of roadside crashes on Thai national highways," Engineering Journal, vol. 17, no. 2, pp. 63-74, 2013.

[6] T. Salatoom and P. Taneerananon, "A study of the flyover-bridge intersection-improved junction," Engineering Journal, vol. 19, no. 1, pp. 1-12, 2015.

[7] T. P. Hsu, M. S. Ahmad Farhan, and N. X. Dao, "A comparison study on motorcycle traffic development in some Asian countries-Case of Taiwan, Malaysia and Vietnam," The Eastern Asia Society for Transportation Studies (EASTS), International Cooperation Research Activity, Tokyo, 2003.

[8] M. S. Horswill and S. Helman, "A behavioural comparison between motorcyclists and a matched group of non-motorcycling car drivers: Factors influencing accident risk," Accident Analysis and Prevention, vol. 35, no. 4, pp. 589-597, July 2003.

[9] S. Stradling, M. Meadows, and S. Beatty, "Characteristics of speeding, violating and thrillseeking drivers," in Traffic and Transport Psychology: Theory and Application, T. Rothengatter and R. D. Huguenin, Eds. Oxford: Elsevier, 2004 , pp. 177-192.

[10] B. C. Watson, D. J. Tunnicliff, K. M. White, C. C. Schonfeld, and D. E. Wishart, "Psychological and social factors influencing, motorcycle rider intentions and behaviour," Australian Transport Safety Bureau, Canberra, ACT, 2007.

[11] R. Elvik, "The power model of the relationship between speed and road safety: Update and new analyses," Institute of Transport Economics, Oslo, Norway, TOI Report 1034, 2009.

[12] D. J. Finch, P. Kompfner, C. R. Lockwood, and G. Maycock, "Speed, speed limits and accidents," Crowthorne, Transport Research Laboratory, 1994

[13] OTP, "Uniformity of traffic control devices and their applications," part 2, book 1-MC lane, 2005.

[14] R. S. Radin Umar, G. M. Mackay, and B. L. Hills, "Preliminary analysis of exclusive motorcycle lanes along the Federal Highway FO2, Shah Alam, Malaysia," Journal of IATSS Research, vol. 19, no. 2 , pp. 93-98, 1995.

[15] H. Hussain, R. S. Radin Umar, M. S. Ahmad Farhan, and M. M. Dadang, "Estimating capacity for uninterrupted motorcycle path in Malaysia," Transportation Research Board 84th Annual Meeting Compendium of Papers, Washington, D.C., USA, 2005.

[16] T. P. Hsu, "Signalized intersections-specifics of motorcycles and motorists-Experiences from Taiwan: Segregated flow concept," Institute of Civil Engineering, National Taiwan University, Taiwan, 2012.

[17] Department of Transport and Main Roads,"Queensland motorcycle rider's guide," 2015.

[18] Daily News. (2011, Apr. 4-5). Setting Up Exclusive Motorcycle Lanes IS Worth The Investment. [Online]. Available: http://www.worldlease.co.th/news-2554069.html

[19] E. H. Elshafei, "Decision-making for roadway lane designation among variable modes," Ph.D. dissertation, University of Maryland at College Park, 2006.

[20] DOH. Highway Accident Information Management System. [Online]. Available: http:// haims.doh.go.th 